\title{
Nano-twin Mediated Plasticity in Carbon-containing FeNiCoCrMn High Entropy Alloys
}

\author{
Z. Wu ${ }^{\mathrm{a}, \mathrm{b}}$, C. M. Parish ${ }^{\mathrm{a}}, \mathrm{H} \cdot \mathrm{Bei}^{\mathrm{a}}{ }^{*}$ \\ a Materials Science and Technology Division, Oak Ridge National Laboratory, Oak \\ Ridge, TN 37831 USA \\ b Materials Science and Engineering Department, University of Tennessee, Knoxville, \\ TN 37996 USA
}

\section{Abstract}

Equiatomic FeNiCoCrMn alloy has been reported to exhibit promising strength and ductility at cryogenic temperature and deformation mediated by nano-twining appeared to be one of the main reasons. We use the FeNiCoCrMn alloy as a base alloy to seek further improvement of its mechanical properties by alloying additional elements, i.e., interstitial carbon. The effects of carbon on microstructures, mechanical properties and twinning activities were investigated in two different temperatures (77 and $293 \mathrm{~K}$ ). With addition of 0.5 at.\% $\mathrm{C}$, the high entropy alloy still remains entirely single phase face-centered cubic (FCC) crystal structure. The materials can be cold rolled and recrystallized to produce a microstructure with equiaxed grains. Both strain hardening rate and strength are enhanced while high uniform elongations to fracture $(\sim 70 \%$ at $77 \mathrm{~K}$ and $\sim 40 \%$ at 293 K) are still maintained. The increased strain hardening and strength could be caused by the promptness of deformation twinning in C-containing high entropy alloys.

* Corresponding Author: Tel.: +1865 576 7196, E-mail address: beih @ ornl.gov (H. Bei) 


\section{Introduction}

Most traditional alloys, such as steels, brasses and bronzes, aluminum alloys, magnesium alloys and $\mathrm{Ni}$ base superalloys, are mainly based on one principle element with addition of minor alloying elements. Recently, an interesting subset of compositionally complex alloys is emerging in which the constituent elements are present in equal- or near-equal-atomic concentrations and therefore "solvent" or "solute" cannot be distinguished [1-13]. Numerous experimental and theoretical investigations have shown that, contrary to the general physical metallurgy intuition (e.g., increasing number of additive elements with very different crystal structures will simultaneously increase the probability that second phases will form) and traditional notions of solid solubility based on empirical rules such as Hume-Rothery, these alloys containing multiple constituent elements in equiatomic or near-equiatomic concentrations tend to crystallize as solid solutions with simple $(\mathrm{FCC}$ or $\mathrm{BCC})$ crystal structures $[3,4]$. One example is equiatomic FeNiCoCrMn alloy, which exhibit single-phase with FCC crystal structure [59]. Since its first exploration in 2004 [5], high thermodynamic stability [6], excellent malleability [7], and slow diffusion [10] have been reported for this alloy. Recent mechanical investigations found that this alloy had both practical and scientific interests from several perspectives. Its yield strength showed an intermediate temperaturedependence that is between pure FCC and BCC metals [11, 12]. Moreover, contrary to most traditional materials in which strength and ductility shows an inverse temperaturedependence, a remarkable increase in strength accompanied by a substantial increase in ductility with decreasing deformation temperature from 293 to $77 \mathrm{~K}$ was observed in this alloy [12]. It also holds remarkable fracture toughness at $77 \mathrm{~K}$, as high as $200 \mathrm{MPa} \cdot \mathrm{m}^{1 / 2}$, which is comparable to the very best cryogenic steels (e.g., austenitic stainless steels and 
high-Ni steels) [13]. The outstanding mechanical properties in cryogenic temperature accompany with the observation of nano-twining formation during plastic deformation.

The nano-twining observation is reminiscent of another group alloys - TwinningInduced-Plasticity (TWIP) steels which have been widely used in automotive industry since its first development of high manganese austenitic steels by Hadfield in 1888 [14]. TWIP steels were found to hold high tensile strength with extraordinary ductility [15-18]. The characterizations of the deformation-microstructure-mechanical property relationship of compositionally different TWIP steels have reasonably attributed the observed promising mechanical properties to the formation of nano-scaled deformation twins which will significantly raise the strain hardening by serving as obstacles to dislocation motion and subdivisions of initial grains into twin-surrounded lamellas [19-22].

Usually in TWIP steels, alloying additions of $\mathrm{C}, \mathrm{Si}$ and/or $\mathrm{Al}$ are needed to obtain the ideal combination of high strength and good uniform elongation due to their capability for triggering nano-twinning in Fe-Mn TWIP steels [23]. Therefore, a similar design concept is used here to seek further improvement of the mechanical properties of FeNiCoCrMn high entropy alloys by alloying. As the first step, carbon will be alloyed to the equiatomic FeNiCoCrMn alloy to investigate its potential of enhancing the mechanical performance. In TWIP steels, the carbon concentration will be normally maintained below 0.6 at.\% in order to obtain a carbide-free, fully austenitic microstructure with lowered stacking fault energy which is uniquely important for the formation of deformation twinning [23]. Thus in the current study, 0.5 at.\% carbon will be added and its effects on the microstructure and mechanical properties of the FeCrNiCoMn high entropy alloys will be investigated. 


\section{Experimental Methods}

Equiatomic FeNiCoCrMn alloys with the addition of 0.5 at.\% $\mathrm{C}$ was produced by arc melting the elements $\mathrm{Fe}, \mathrm{Ni}, \mathrm{Co}, \mathrm{Cr}, \mathrm{Mn}(>99.9 \%$ pure) and graphite powder in a watercooled copper crucible under Ar atmosphere. Rectangular ingots measuring $12.7 \mathrm{~mm} \times$ $12.7 \mathrm{~mm} \times 127 \mathrm{~mm}$ were produced by drop-casting the melts into copper molds. The ingots were homogenized for 24 hours at $1473 \mathrm{~K}$, followed by an air-cooling. They were then cold rolled along the longitudinal ingot direction to a total thickness reduction of $86 \%$ without intermediate annealing. Flat dog-bone-shaped specimens with a gage length of $10 \mathrm{~mm}$ were cut from the cold-rolled sheets with their longitudinal axes perpendicular to the rolling direction followed by recrystallized at $1100{ }^{\circ} \mathrm{C}$ for 1 hour. Before the tensile tests, all faces of sample gage sections were ground through 600-grit SiC paper and nine Vickers microhardness indents spaced $1 \mathrm{~mm}$ apart were made along the gage lengths using a LECO LM $100_{A T}$ Vickers Hardness tester with a force of $200 \mathrm{~g}$. These preexisting indents will be used to identify the uniform elongations to fracture $\left(\mathrm{e}_{f}\right)$ by averaging the change in the distance between adjacent indents. Tensile tests were performed with a screw-driven mechanical testing machine (Instron) at an engineering strain rate of $10^{-3} \mathrm{~s}^{-1}$ and temperatures of 77 and $293 \mathrm{~K}$. For each temperature, three specimens were conducted to rupture to obtain the stress-strain curve, and four specimens were tensile tested and stopped at stains of $6.5 \%, 13 \%, 19.5 \%, 32.5 \%$ to study the microstructural evolution during plastic deformation. X-ray diffraction was performed on the gage sections of fractured specimens to determine whether any phase transformation or second phase precipitation had occurred.

Hitachi S4800 field emission gun (FEG)-SEM and 6500 F JEOL FEG-SEM equipped 
with a TSL OIM EBSD system were used to characterize the microstructures of the asannealed and deformed materials. The EBSD measurements were performed with an electron probe current of $3.0 \mathrm{nA}$ at an acceleration voltage of $20 \mathrm{kV}$, with step size of 20 $\mathrm{nm}$ (high magnification) or $300 \mathrm{~nm}$ (low magnification). TSL OIM V7 ${ }^{\mathrm{TM}}$ software was used for qualification and analysis of the EBSD results. EBSD maps are displayed as inverse pole figure (IPF) maps in the direction of the rolling direction (for the initial microstructure) or tensile axis (for the tensile-deformed microstructure). Data "cleaning" procedures [24] were not used.

\section{Results}

The microstructure of FeNiCoCrMn-0.5C sample annealed at $1100{ }^{\circ} \mathrm{C}$ for 1 hour after cold rolling is shown in Fig. 1a, which is electron backscatter diffraction (EBSD) inverse pole figure (IPF) map. Only the FCC solid solution phase was found. As can be seen in the figure, the annealed material contains homogeneous equiaxed grain microstructure without strong texture. Similar to the equiatomic FeNiCoCrMn alloy [12], annealing twins are visible in many grains in the carbon-contained alloys and the thickness of the annealing twin is in the tens $\mu \mathrm{m}$ scales. The average grain size without twin boundaries determined by a linear intercept method was found to be $\sim 115 \mu \mathrm{m}$. The FCC singlephase structure was revealed by X-ray diffraction to remain stable during deformation at room temperature and liquid nitrogen temperature: no evidence of phase transformation or second-phase precipitation was detected after mechanical testing.

Figure $1 \mathrm{~b}$ shows representative engineering stress vs. plastic strain curves of the 
FeNiCoCrMn- $0.5 \mathrm{C}$ alloy tested at both temperatures; and for comparison, the curves of FeNiCoCrMn alloy with similar grain size is also included in the figure [12]. The $0.2 \%$ offset yield strengths $\left(\sigma_{y}\right)$, ultimate tensile strengths (UTS), uniform elongations to fracture $\left(\mathrm{e}_{f}\right)$ and extent of work hardening $\left(\Delta \sigma=\mathrm{UTS}-\sigma_{\mathrm{y}}\right)$ were summarized in Table I. Similar to the equiatomic FeNiCoCrMn alloy; both strength and ductility increase significantly when the deformation temperature decreases form 293 to $77 \mathrm{~K}$. Carbon additions significantly increase yield strength and UTS of the materials with the uniform elongations to fracture remain high values of $\sim 70 \%$ and $\sim 40 \%$ at 77 and $293 \mathrm{~K}$, respectively. For example, by adding 0.5 at. $\%$ carbon, the 77 K-UTS is increased by $33 \%$ from 820 to $1090 \mathrm{MPa}$; and the $293 \mathrm{~K}$-UTS is increased by $26 \%$ from 520 to $655 \mathrm{MPa}$. One distinct feature that can be immediately seen from the stress-strain curves (Fig. 1b) is the largely enhanced average slope of the plastic region, which could be an indication of the average strain hardening rate, for the carbon-containing alloy compared to that for the carbon-free FeNiCoCrMn alloy.

The EBSD maps showing the microstructures of the FeNiCoCrMn-0.5C alloy tensiledeformed to different engineering strains $(6.5 \%, 13 \%, 19.5 \%, 32.5 \%)$ were shown in Figure 2. The grains still remain equiaxed when the strain are small $(6.5 \%$ or $13 \%)$ and become elongated along the tensile direction with further straining. The initial material (Fig. 1a) shows nearly equiaxed grain structures. As plastic deformation occurs in the grains, orientation fluctuations appear quickly, even after only 6.5\% strain (Fig. 2a-2b), and these in-grain orientation variations increase with increasing strain (Fig. 2c-2j), indicating that plastic tensile deformation generated dislocations and caused these misorientations. The range of crystal orientation within a grain increases with the level of 
the plastic deformation due to the increased density of the stored dislocations [25]. Another feature is that with increasing strain, the grains are highly distorted and exhibit orientations mainly with the $<1 \quad 1 \quad 1>$ - or $<100>$ - crystallographic direction parallel to the tensile axis.

For the FeNiCoCrMn-0.5C alloy, when it was deformed at $77 \mathrm{~K}$, at an engineering strain of $6.5 \%$, near-equally spaced individual twins with a width of $\sim 10 \mathrm{~nm}$ were revealed by back-scattered SEM (Fig. 3). These twins nucleated at grain boundaries and do not extend to the opposite grain boundary, but only grow partially into the grain interior, without impinging on other interfaces. A magnified view of these areas shows that some of the twins will be bundled and form twin bands with $\sim 100 \mathrm{~nm}$ thickness. It is noted that failure to reveal the existence of deformation twin (bands) using EBSD (Fig. 2a) could be caused by the low density of mechanical twins at this level of strain and a much smaller width of individual twins $(\sim 10 \mathrm{~nm})$ and thickness of the twin bundle ( $100 \mathrm{~nm})$ compared to the EBSD scanning step size $(300 \mathrm{~nm})$. At $13 \%$ engineering strain, a few band-like features in some $<1 \quad 1 \quad 1>/ /$ TA $(<1 \quad 1 \quad 1>$ direction aligned to the tensile axis) oriented grains (Fig. 2c) were observed. To have a better visualization of these bands, the selected area was magnified and slow scan with a step size of $20 \mathrm{~nm}$ was conducted. The corresponding high-magnification Kikuchi pattern quality (KPQ) map (Fig. 4a) composed of numerous straight dark lines in a micron-scale band (indicated with red line). To identify details of the band, misorientation along the red line in Fig.1a was measured and the results was plotted in Fig. 4b. It shows that whenever the scan passes the lines, there will be a $60^{\circ}$ misorientation, indicating that these bands are composed of $\Sigma 3$ twins. Some smaller bands may be missed due to the limited spatial 
resolution of EBSD [26]. When the strain was increased to $19.5 \%$, the density of thin parallel bands was remarkably increased and they are with various width and observed in both $<1 \quad 1 \quad 1>$ grains and those with certain deviation (Fig. 2e). These bands are also identified to be $\Sigma 3$ twins with $60^{\circ}$ misorientation with their surroundings. The BSE image (Fig. 5) shows that the microstructures are full of parallel bands with $\sim 2 \mu \mathrm{m}$ spacing; and each band consists of numerous nano-twins with $\sim 10 \mathrm{~nm}$ thickness. Another striking feature is that the grains that are dominated by twinning bands also exhibit a secondary twinning system. When the strain is further increased to $32.5 \%$, more grains are dominated by twinning bands with much smaller spacing (Fig. 2g). Interaction between two twinning systems was also observed (Fig. 2g and Fig. 6). When the material was further strained to failure, twin density continuously increases and a colony-like morphology is formed (Fig. 2i). The colony consists of deformation twins with varying thicknesses and spacings. Only a few parts of the microstructure are free of twin bands. A majority of grains exhibit a secondary twinning system.

As the deformation temperature increases from 77 to $293 \mathrm{~K}$, the appearance of twinning is postponed. Both high-magnification BSE images and EBSD cannot reveal the existence of deformation twin for samples tensile-deformed to an engineering strain lower than $32.5 \%$. At $32.5 \%$ tensile strain, a few sparsely distributed twin bands were observed (Fig. 2h). When the material was continuously deformed to fracture, the twin volume fraction increases significantly with the observation of denser and thicker twin bundles generated by more than one twinning systems. 


\section{Discussion}

The current investigations indicate that the plastic deformation of the current alloy is strongly mediated by nano-twinning. A schematic illustration of the twinning activity as a function of tensile strain is shown in Figure 7. At the early stage of deformation, dislocation accumulation along the grain boundaries nucleates nano-scaled primary twins at the boundaries once a critical stress is reached. The number of twins increases with strain while their individual thickness remains almost constant. Numerous twins will bundle together to form twin bands. Gradually, the thick twin bands will occupy almost all grain volume. When the tensile strain is further increased, more and more twins will bundle together and simultaneously or subsequently the secondary twinning systems will be activated. More and more grains will show more than one twinning systems. The twins generated from different systems will interact with each other, making a zig-zag-like microstructure.

The factors that have potential of affecting the above-mentioned twinning activities will definitely influence mateirals' mechanical performance (e.g., strain hardening). There is clear evidence from the current study that a few factors will affect the twinning activities, including alloying addition, grain orientation, and temperature. Thus, each of these will be discussed separately.

Carbon effects. In the base-alloy FeNiCoCrMn, at $77 \mathrm{~K}$, nano-twinning was observed after $\sim 20 \%$ strain and act as additional deformation mode. When the alloy was deformed beyond $\sim 38 \%$ engineering strain, additional twinning systems were activated in the $\{11$ 
1) twinning planes. No nano-twinning was observed for the FeNiCoCrMn alloy tensilestrained at $293 \mathrm{~K}$ [12]. Compared to these observations, when the material is alloyed with 0.5 at.\% carbon, the activation of primary and secondary twinning systems occurs at much lower strains (6.5\% and $19.5 \%$, respectively) at $77 \mathrm{~K}$. Extensive twinning is even observed when the material is deformed to fracture at $293 \mathrm{~K}$. All of these observations suggest more pronounced twinning activities in the FeNiCoCrMn- $0.5 \mathrm{C}$ alloy than that in the FeNiCoCrMn alloy. Because of the strong solid solution hardening of the carbon interstitial atom in HEAs, the dislocation mediated plasticity (slips) become much more difficult in the C-containing HEAs; thus, the critical stress needed to activate twinning can be easily achieved at relatively early stage of deformation. In addition, the intrinsic stacking fault energy has been known to be an essential parameter determining the tendency of twinning. Twinning will be more pronounced in materials with lower the stacking fault energy. Similar to the effects of $\mathrm{C}$ on the stacking fault energy of Fe-based materials (e.g., austenitic steel [27]), the current observations suggested that the stacking fault energy of the equiatomic FeNiCoCrMn alloy is decreased by the addition of C.

This enhanced twinning may explain the higher engineering strains needed to achieve the maximum tensile stress in the $\mathrm{C}$-free $\mathrm{FeNiCoCrMn}$ equiatomic alloy compared to the 0.5 at $\%$-FeNiCoCrMn alloy. Specifically, in C-free FeNiCoCrMn, the maximum tensile stresses were achieved at $\sim 85 \%$ strain $(77 \mathrm{~K}, 820 \mathrm{MPa})$ and $\sim 65 \%$ strain $(293 \mathrm{~K}, 520$ MPa), compared to $70 \%$ strain (77 K, $1090 \mathrm{MPa}$ ) and $40 \%$ strain $(293 \mathrm{~K}, 655 \mathrm{MPa}$ ) in the 0.5 at $\%$ C alloy.

A detailed explanation to the correlation between the twinning activity and strain hardening is given below. Annealing twins have their thickness of more than $10 \mu \mathrm{m}$, 
therefore their obstacles to dislocation movement is weak [28]. In contrast, the nonbundled thin mechanical twins (normally in a few to tens nm scales) formed with a low density (e.g., some individual twins observed in FeNiCoCrMn-0.5C alloy at 6.5\% strain (Fig. 4a) will be able to serve as effective obstacles to dislocation motion. They can act as even stronger obstacles than single twins once they are arranged in bundle (e.g., >13\%) due to the higher critical stress required to carry plastic deformation across the twin bundle than that required to penetrate an individual twin. Furthermore, interactions between dislocations and twins will cause the accumulation of a high density of sessile dislocations within the twin lamellae, leading to increased twin strength with deformation. These accumulated dislocations are potentially effective barriers to dislocation motion and can provide additional strengthening within the induced mechanical twins and increase the critical stress required to induce plastic deformation across the twins $[29,30]$. A map revealing short-range orientation gradients were shown in Figure 8a, supporting the hypothesis of dislocation accumulation around the twin boundaries. The orientation gradients were highlighted using the Kernel parameter for the first neighbors which is the average misorientation angle between the current pixel orientation and its six first neighbors. The corresponding scanned area was marked in Fig. $2 \mathrm{i}$ by the arrow. The results show that the orientation variations exhibit higher values near twin boundaries. This could be caused by the twin-slip interactions and may indicate the dislocation pile-up at the twin boundaries. With increasing strain, the development of a dense twin substructure (Fig. $2 \mathrm{~g}$ and $2 \mathrm{i}$ ), the cutting of twin boundaries through dislocation substructure and the interactions between primary and secondary twinning systems will result in a further microstructure refinement. The effect is often referred to 
as a "dynamic Hall-Petch effect" [31-36]. Figure 8b provides a further microstructural support of this effect. Upon failure at $77 \mathrm{~K}$, their microstructures are separated by twin (lamellae) boundaries into numerous tiny twin-free areas due to the intensive interactions between twin bands from different twinning systems. Because the deformation-twin boundaries will able to serve as dislocation-motion obstacles, each twin-surrounded area will act as a "grain", making the "effective grain size" much smaller than the real grain size.

Grain orientation effects. A strong orientation-dependence of the twinning activities was observed. Under tension, twinning tends to be activated on the $<111>/ /$ TA oriented grains and those with certain deviations. Similar observations have been reported for a few face-centered cubic metal and alloys, including $\mathrm{Cu}$ [37], $\mathrm{Ag}-\mathrm{Au}$ alloys [38], and polycrystalline Fe-33Mn-3Al-3Si [39], Fe-31Mn-3Al-3Si [40], and Fe-22Mn-0.6C [41] TWIP steels. In all of these materials, deformation twinning readily occurred when the tensile axis lay near [ $\left[\begin{array}{lll}1 & 1 & 1\end{array}\right]$ direction, whereas no deformation twinning was observed for the orientation lying near the $\left[\begin{array}{lll}0 & 0 & 1\end{array}\right]$. These dependencies of the mechanical twinning activation on the grain orientation have been explained by assuming that the critical resolved shear stress for slip is identical to that for mechanical twinning [39, 41, 42]. In this case, grains with different orientations will have different preferred deformation mechanism and this could be evaluated by comparing the Schmid factors for dislocation slip and mechanical twinning. Under tension conditions, in grains with their $<1 \quad 1 \quad 1>$ directions aligned to the tensile axil (TA), the Schmid factor for the mechanical twinning (0.31) is larger than that for dislocation slip (0.27); while in $<001>/ /$ TA oriented grains the Schmid factor for dislocation slip (0.41) is larger than that for deformation twinning 
(0.24) [42]. Another explanation is based on the assumption that the formation of mechanical twinning is governed by the dissociation of glide dislocations into Shockley partials only [43]. In this case, the degree of separation of two moving Shockley partials (leading and trailing partials) will be one of the most important factors determining the twin formation. It was suggested that the steady-state separation of a glide dislocation (width of partial separation) will show strong orientation dependence, and in $\langle 111>$ oriented grains, complete dissociation of the Shockley pair will occur with the production of stacking faults, but in $<0 \quad 0 \quad 1>$ oriented grains, the dislocation pair will experience a constriction [44, 45]. Convincing microstructural evidence was provided by Idrissi [46] to show that these stacking faults can act as precursors for the formation of deformationinduced twins. Further study is needed to have a complete understanding of this.

Temperature effects. The temperature effects on twinning can also be clearly seen by comparing the microstructures of the investigated alloy at different temperatures. For the FeNiCoCrMn-0.5C alloy, while it was deformed at $293 \mathrm{~K}$, the appearance of deformation twinning occurs at an engineering strain of $32.5 \%$ while twinning happens at very early stages of deformation (e.g., 6.5\%) at $77 \mathrm{~K}$. The activation of secondary twinning systems occurs also at a much earlier stage when the materials are strained at lower temperatures. The deformation temperature may influence the twinning ability through several different ways. First, it has been widely accepted that there exist a critical stress that needs to be reached in order to activate deformation twinning [47-50]. Under higher temperatures (e.g., $293 \mathrm{~K}$ ), this stress will be more difficult to reach due to the lower yield strength or dynamic recovery. However, when the deformation temperature is lower (e.g., to $77 \mathrm{~K}$ ), the dynamic recovery is reduced, and the yield strength will increase (Fig. 2 and Table 1). 
The increased yield strength will make it easier to reach the critical stress at lower strain. Second, deformation temperature will affect twinning by changing the stacking fault energy of material. Stacking fault energy decrease at lower temperature and will cause more twinning.

\section{Summary and Conclusions}

The alloying design strategy of TWIP steels is successfully applied to a newly developed single-phase FCC high entropy alloy, FeNiCoCrMn, which has been shown to exhibit promising strength and ductility for cryogenic applications. To achieve this end, carbon is added to modify its microstructure (e.g., twinning activity) and thus mechanical properties (e.g., strain hardening). The microstructures and mechanical properties were characterized as a function of temperature, strain and carbon concentration. The results were compared with those of previous-reported on the base alloy-FeNiCoCrMn. Based on current results and analyses, the following conclusions could be drawn:

(1) Adding 0.5 at. $\%$ carbon will not change the single-phase feature of equiatomic FeNiCoCrMn alloy during casting, homogenization, cold-rolling, annealing or further tensile-straining.

(2) For 0.5 at.\% C-containing FeNiCoCrMn alloy, both strength (yield strength and ultimate tensile strength) and ductility generally increase with decreasing temperature with more pronounced difference between 293 and $77 \mathrm{~K}$.

(3) Both yield strength and ultimate tensile strength were increased by the addition of 0.5 at.\% carbon concentration while a reverse trend was observed for the uniform 
elongation, indicating a negative dependence of average strain rate on carbon concentration.

(4) The increased strain hardening and strength could be caused by the promptness of deformation twinning in C-containing high entropy alloys. The twinning ability and activities were found to be affected by a few factors, including grain orientation, temperature and carbon concentration. Under current tensile condition, twinning is more pronounced in grains with their $\langle 111>$ directions aligned with the tensile axle; while in $<001$ 1 //TA oriented grains twinning rarely occurs. Twinning activities are enhanced by decreasing deformation temperature and increasing carbon addition. Further investigations are needed to have a thorough understanding of these dependencies.

\section{Reference:}

[1] Yeh JW, Chen SK, Lin SJ, et al. "Nanostructured high-entropy alloys with multiple principal elements: Novel alloy design concepts and outcomes, " Adv Eng Mater 2004; 6: 299.

[2] Guo W, Dmowski W, Noh JY, et al. "Local atomic structure of a high-entropy alloy: an X-ray and neutron scattering study," Metall Mater Trans A 2013; 44: 1994.

[3] Guo S, Liu CT. " Phase stability in high entropy alloys: Formation of solidsolution phase or amorphous phase" Prog in Nat Sci: Mat International 2011; 21: 433.

[4] Yang X, Zhang Y. " Prediction of high-entropy stabilized solid-solution in multi component alloys, " Mater Chem Phys 2012, 132: 233.

[5] Cantor B, Chang ITH, Knight P, et al. "Microstructural development in equiatomic multicomponent alloys," Mater Sci Eng A 2004; 375-377: 213. 
[6] Gali A, George EP. "Tensile properties of high- and medium-entropy alloys" Intermetallics 2013; 39: 74.

[7] Otto F, Yang Y, Bei H, et al. " Relative effects of enthalpy and entropy on the phase stability of equiatomic high-entropy alloys" Acta Mater 2013; 61: 2628.

[8] Wu Z, Bei H, Otto F, et al. " Recovery, recrystallization, grain growth and phase stability of a family of FCC-structured multi-component equiatomic solid solution alloys," Intermetallics 2014; 46: 131.

[9] Zhu C, Lu ZP, Nieh TG. "Incipient plasticity and dislocation nucleation of FeCoCrNiMn high-entropy alloy,” Acta Mater 2013; 61(8): 2993.

[10] Chang SY, Li CE, Huang YC, et al. " Structural and Thermodynamic Factors of Suppressed Interdiffusion Kinetics in Multi-component High-entropy Materials " Scientific Reports 2014; 4: 4162

[11] Wu Z, Bei H, Pharr GM, et al. " Temperature dependence of the mechanical properties of equiatomic solid solution alloys with face-centered cubic crystal structures " Acta Mater 2014; 81: 428.

[12] Otto F, Dlouhy A, Somsen Ch, et al. "The influences of temperature and microstructure on the tensile properties of a CoCrFeMnNi high-entropy alloy," Acta Mater 2013; 61: 5743.

[13] Gludovatz B, Hohenwarter A, Catoor D, et al. "A fracture-resistant high-entropy alloy for cryogenic applications," Science 2014; 345: 1153.

[14] News \& Comment. "HADFIELD'S MANGANESE STEEL" Science 1888; 12: 284.

[15] Frommeyer G, Brüx U, Neumann P. "Supra-ductile and high-strength manganeseTRIP/TWIP steels for high energy absorption purposes," ISIJ Int 2003; 43: 438.

[16] Grässel O, Frommeyer G, Derder C, Hofmann H." Phase transformations and mechanical properties of Fe-Mn-Si-Al TRIP-steels," J Phys IV 1997; 7: 383.

[17] Grässel O, Krüger L, Frommeyer G, Meyer L. "High strength Fe-Mn-(Al, Si) TRIP/TWIP steels development-properties-application," Int J Plast 2000; 16: 1391.

[18] Allain S, Chateau JP, Bouaziz O. "A physical model of the twinning-induced plasticity effect in a high manganese austenitic steel, "Mater Sci Eng A 2004; 387: 143. 
[19] Allain S, Chateau JP, Bouaziz O, Migot S, Guelton N. "Correlations between the calculated stacking fault energy and the plasticity mechanisms in Fe-Mn-C alloys," Mater Sci Eng A 2004; 387: 158.

[20] Yen HW, Huang M, Scott C, Yang JR. "Interactions between deformation-induced defects and carbides in a vanadium-containing TWIP steel," Scr Mater 2012; 66: 1018.

[21] Scott C, Allain S, Faral M, Guelton N. "The development of a new Fe-Mn-C austenitic steel for automotive applications," Rev Metall 2006; 103: 293.

[22] Kang S, Jung YS, Jun JH, Lee YK. "Effects of recrystallization annealing temperature on carbide precipitation, microstructure, and mechanical properties in Fe-18Mn-0.6C-1.5Al TWIP steel," Mater Sci Eng A 2010; 527: 745.

[23] Cooman BC, Chin K, Kim J. "High Mn TWIP Steels for Automotive Applications" In: Chiaberge M., editor, New Trends and Developments in Automotive System Engineering. 2011. Intech.

[24] Brewer LN, Michael JR. " Risks of 'Cleaning' Electron Backscatter Diffraction Data," Microscopy Today 2010; 18: 10.

[25] Kamaya M. Wilkinson AJ, Titchmarsh JM. "Measurement of plastic strain of polycrystalline material by electron backscatter diffraction," Nuclear Eng \& Design 2005; 235 : 713.

[26] Steinmetz DR, Zaefferer S. "Towards ultrahigh resolution EBSD by low accelerating voltage," Mat Sci \& Tech 2010; 26: 640.

[27] Addasi A, Dick A, Hickel T, et al. "First-principles investigation of the effects of carbon on the stacking fault energy of Fe-C alloys," Acta Mater 2011; 59: 3041.

[28] Hendrickson AA, Fine ME. "Solid solution strengthening of Ag by Al," Trans AIME 1961; 221: 967.

[29] Christian JW, Mahajan S. "Deformation Twinning," Prog in Mat Sci 1995; 39: 1.

[30] Reed-Hill RE, Hirth JP, Rogers HC. Deformation Twinning. Gordon and Breach Science 1964.

[31] Rémy L. "Kinetics of FCC Deformation Twinning and its Relationship to Stressstrain Behavior," Acta Metall 1978; 26: 443. 
[32] Asgari S, El-Danaf E, Kalidindi R, Doherty R. "Strain hardening regimes and microstructural evolution during large strain compression of low stacking fault energy fcc alloys that form deformation twins," Metall Mater Trans A 1997; 28: 1781.

[33] Rohatgi A, Vecchio KS, Gray GT. "The influence of stacking fault energy on the mechanical behavior of $\mathrm{Cu}$ and $\mathrm{Cu}-\mathrm{Al}$ alloys: Deformation twinning, work hardening, and dynamic recovery," Metall Mater Trans A 2001; 32: 135.

[34] Beladi H, Timokhina IB, Estrin Y, Kim J, De Cooman BC, Kim SK. "Orientation dependence of twinning and strain hardening behaviour of a high manganese twinning induced plasticity steel with polycrystalline structure," Acta Mater 2011; 59: 7787.

[35] Rémy L, Pineau A. "Twinning and Strain-induced FCC-HCP Transformation on Mechancical-properties of Co-Ni-Cr-Mo Alloys," Mater Sci Eng 1976; 26: 123.

[36] Gutierrez-Urrutia I, Raabe D. "Dislocation and twin substructure evolution during strain hardening of an Fe-22 wt.\% Mn-0.6 wt.\% C TWIP steel observed by electron channeling contrast imaging," Acta Mater 2011; 59: 6449.

[37] Blewitt TH, Coltman RR, Redman JK. "Low-Temperature Deformation of Copper Single Crystals," J Appl Phys 1957; 28: 651.

[38] Suzuki H, Barrett CS."Deformation Twinning in Silver-Gold Alloys" Acta Metall $1958 ; 6: 156$.

[39] Yang P, Xie Q, Meng L, Ding H, Tang Z, "Dependence of deformationtwinning on grain orientation in a high manganese steel " Scr Mater 2006; 55: 629.

[40] Ueji R, Tsuchida N, Terada D, Tsuji N, et. al. "Tensile properties and twinning behavior of high manganese austenitic steel with fine-grained structure," Scr Mater 2008, 59: 963.

[41] Gutierrez-Urrutia I, Zaefferer S, Raabe D, "The effect of grain size and grain orientation on deformation twinning in a Fe-22 wt.\% Mn-0.6 wt.\% C TWIP steel," Mater Sci Eng A 2010; 527: 3552.

[42] Lee YK. "Microstructural evolution during plastic deformation of twinninginduced plasticity steels," Scr Mater 2012; 66: 1002.

[43] Copley SM, Kear BH. "Dependence of Width of a Dissocaiated Dislocation on 
Dislocation Velocity," Acta Metall 1968;16: 227.

[44] Goodchild D, Roberts WT, Wilson DV. "Plastic Deformation and Phase Transformation in Textured Austenitic Stainless steel," Acta Metall 1970;18:1137.

[45] Kestenbach HJ. "Effect of Applied Stress on Partial Dislocation Separation and Dislocation Substructure in Austenitic Stainless Steel," Phil Mag 1977; 36:1509.

[46] Idrissi H, Ryelandt L, Veron M, Schryvers D, Jacques PJ. " Is there a relationship between the stacking fault character and the activated mode of plasticity of Fe-Mnbased austenitic steels?" Scr Mater 2009; 60: 941.

[47] Venables JA. "Nucleation + Propagation of Deformation Twins," J Phys Chem Solids 1964; 25: 693.

[48] Meyers MA, Vöhringer O, Lubarda VA. "The onset of twinning in metals: A constitutive description," Acta Mater 2001; 49: 4025.

[49] Frank FC, Thompson N. "On Deformation by Twinning," Acta Metall 1955; 3: 30.

[50] Efstathiou C, Sehitoglu H."Strain hardening and heterogeneous deformation during twinning in Hadfield steel" Acta Mater 2010; 58: 1479

\section{Acknowledgments}

This work was supported by the US Department of Energy, Office of Science, Basic Energy Sciences, Materials Sciences and Engineering Division. 


\section{Tables:}

Table I: $0.2 \%$ offset yield stress $\left(\sigma_{\mathrm{y}}\right)$, the ultimate tensile strength (UTS), the uniform elongation to fracture $\left(\mathrm{e}_{\mathrm{f}}\right)$, extent of work hardening for the investigated alloy $\left(\Delta \sigma=\mathrm{UTS}-\sigma_{\mathrm{y}}\right)$.

\begin{tabular}{|c|c|c|c|c|}
\hline & \multicolumn{2}{|c|}{ FeNiCoCrMn [12] } & \multicolumn{2}{c|}{ FeNiCoCrMn-0.5C } \\
\hline & $77 \mathrm{~K}$ & $293 \mathrm{~K}$ & $77 \mathrm{~K}$ & $293 \mathrm{~K}$ \\
\hline$\sigma_{\mathrm{y}}(\mathrm{MPa})$ & 350 & 165 & 510 & 225 \\
\hline $\mathrm{UTS}(\mathrm{MPa})$ & 820 & 520 & 1090 & 655 \\
\hline $\mathrm{e}_{\mathrm{f}}(\%)$ & 85 & 65 & 69 & 38 \\
\hline$\Delta \sigma(\mathrm{MPa})$ & 470 & 355 & 590 & 430 \\
\hline
\end{tabular}




\section{Figure Captions:}

Fig. 1. (a) Microstructure of FeNiCoCrMn-0.5C alloy annealed at $1100{ }^{\circ} \mathrm{C}$ for 1 hour after cold-rolling; coloring is the inverse pole figure map projected on rolling direction (horizontal) (b) Engineering stress vs. plastic strain as a function of temperature for $\mathrm{FeNiCoCrMn}-0.5 \mathrm{C}$ alloys, for comparison, the stress-stain curve of the C-free FeNiCoCrMn with grain size of $155 \mu \mathrm{m}$ [12] is also included.

Fig. 2. EBSD images of FeNiCoCrMn-0.5C alloy shows the twining evaluations as a function of strains at two different temperatures of (a, c, e, g, i) $293 \mathrm{~K}$ and (b, d, $\mathrm{f}, \mathrm{h}, \mathrm{j}) 77 \mathrm{~K}$. Coloring is the inverse pole figure map projected on tensile direction (horizontal)

Fig. 3. Back-scatter electronic image of FeNiCoCrMn-0.5C alloy deformed at $6.5 \%$ strain at $77 \mathrm{~K}$.

Fig. 4. (a) High-magnification Kikuchi pattern quality (KPQ) map of FeNiCoCrMn$0.5 \mathrm{C}$ alloy tensile-deformed at $13 \%$ engineering strain at $77 \mathrm{~K}$; (b) corresponding misorientation as a function of distance for the red line.

Fig. 5. Backscatter electron image of FeNiCoCrMn-0.5C alloy tensile-deformed at $19.5 \%$ engineering strain at $77 \mathrm{~K}$.

Fig. 6. Backscatter electron image of FeNiCoCrMn-0.5C alloy tensile-deformed at $32.5 \%$ engineering strain at $77 \mathrm{~K}$.

Fig. 7. Schematic illustration shows the evolution of twinning activities as a function of strain. For simplicity, the change of grain shape with deformation is not sketched.

Fig. 8. (a) The kernel average misorientation map showing the degree of orientation gradients between the current pixel orientation and its six first-nearest neighbors, and (b) the combined index of image quality and inverse pole figure (projected onto tensile axil) map of the selected area arrow-marked in Figure $2 \mathrm{i}$. 
Figure 1

Click here to download high resolution image
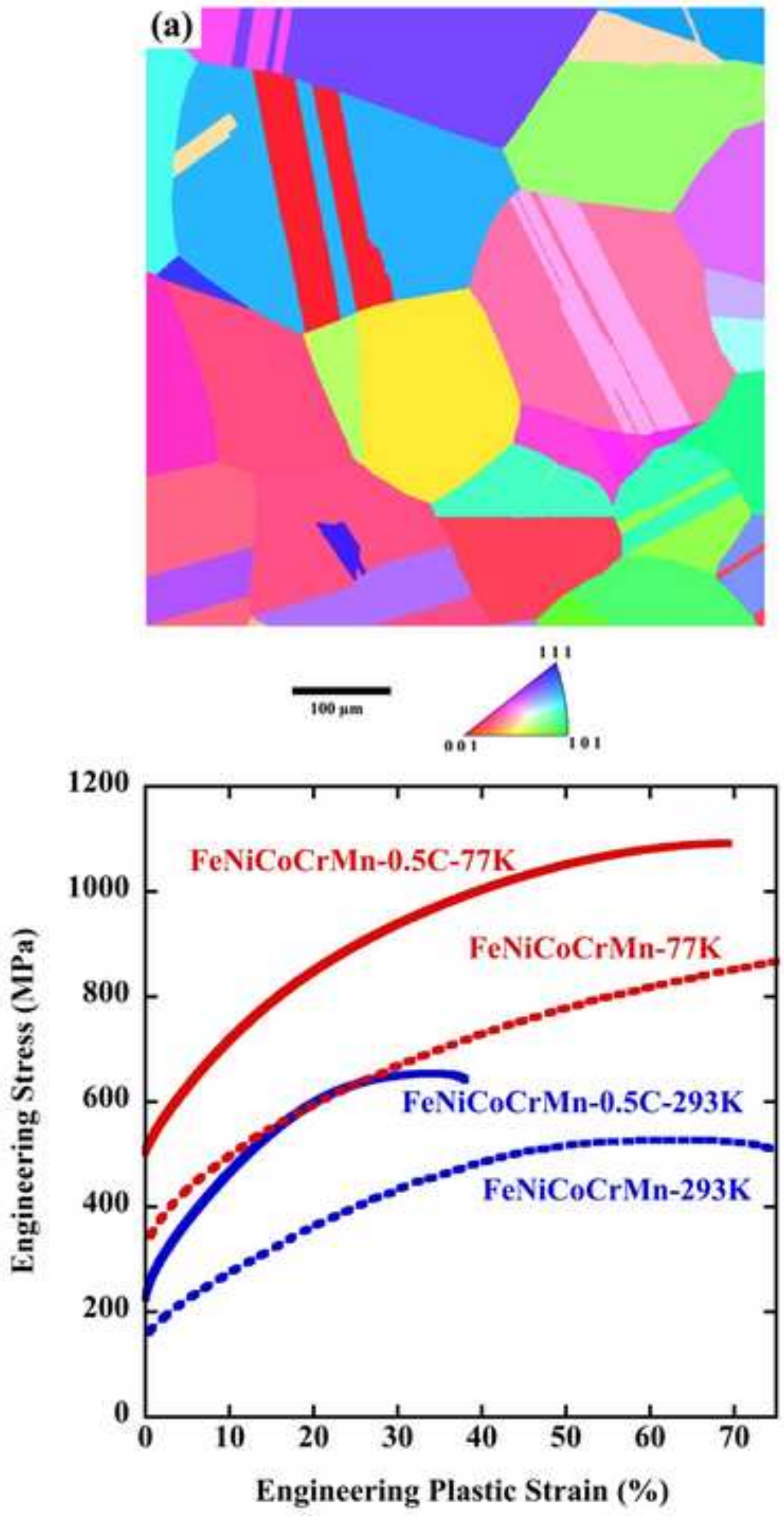
Figure 2
Click here to download high resolution image

$77 \mathrm{~K}$

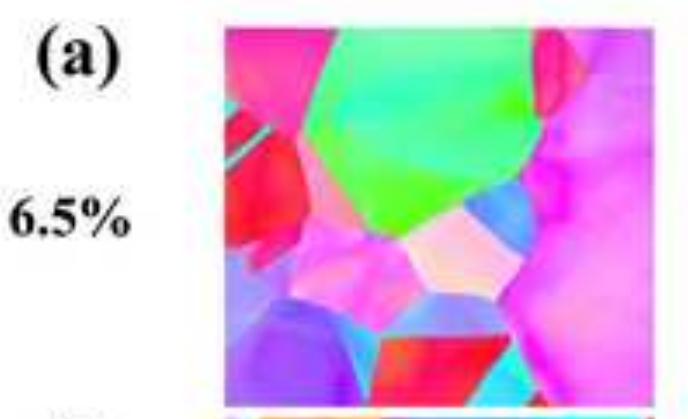

(c)

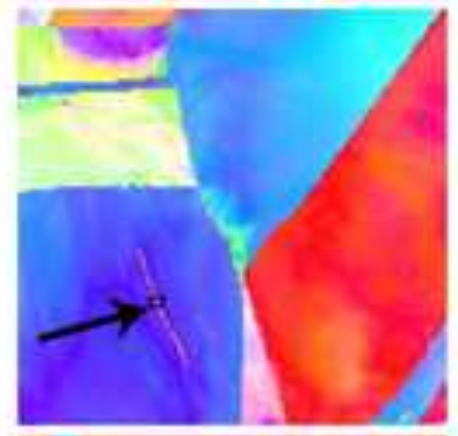

(e)

$13 \%$

(g)

$32.5 \%$

(i)

\section{failure}
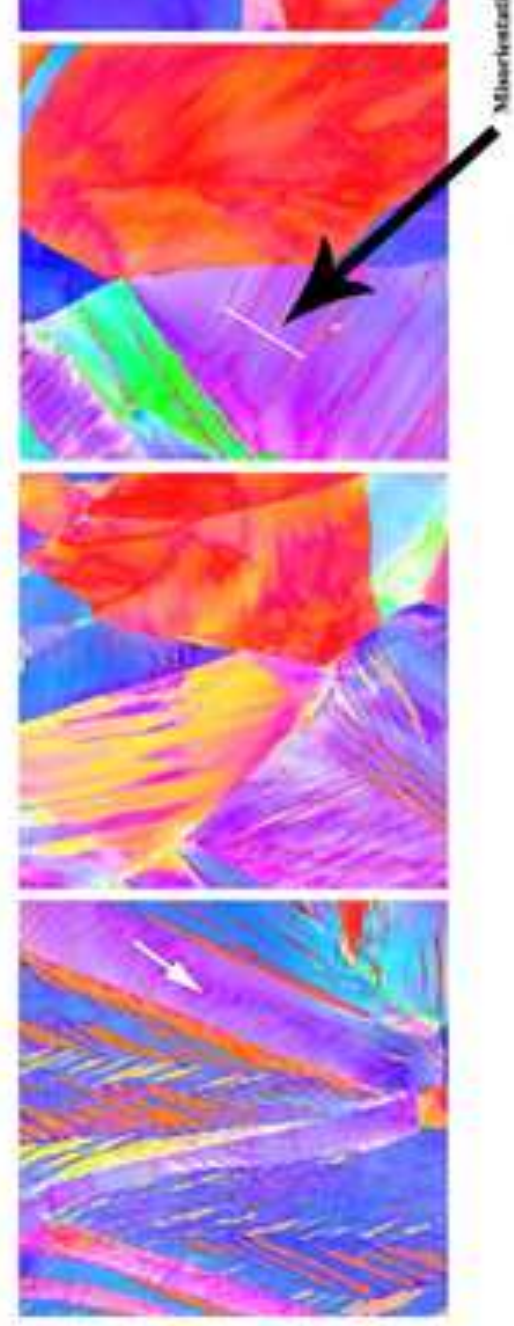

$293 \mathrm{~K}$

(b)

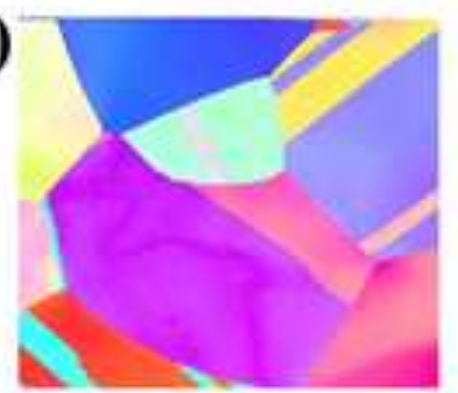

(d)

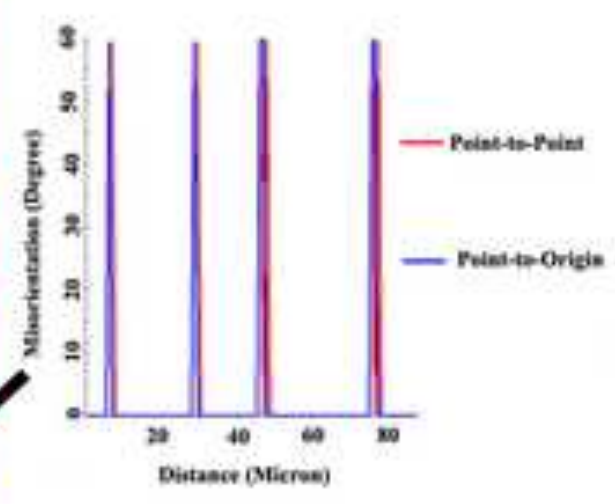

(f)
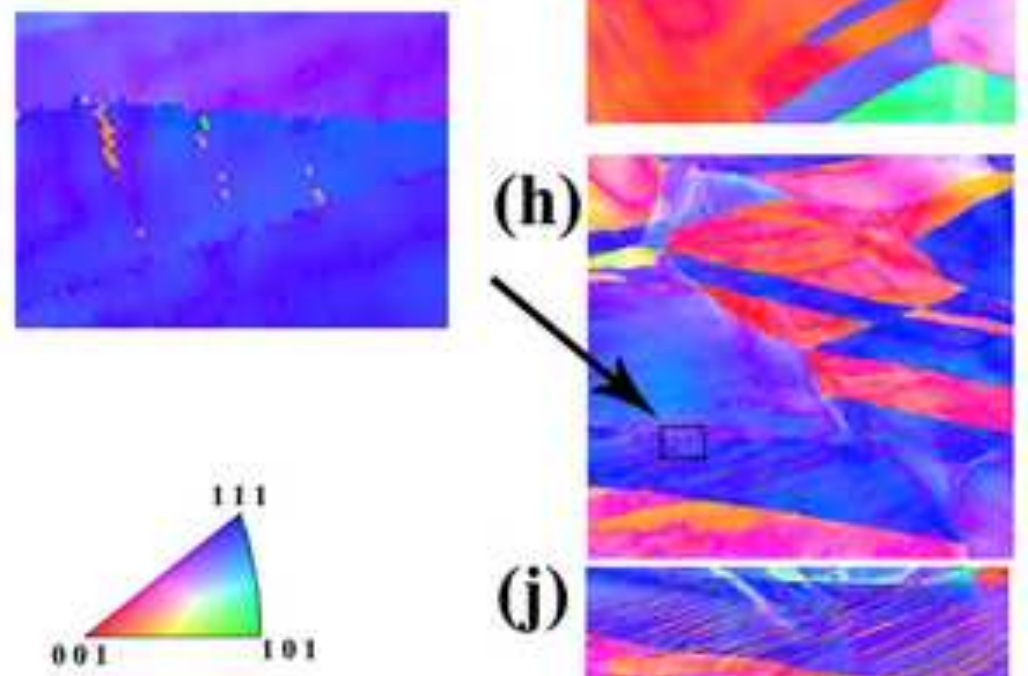

(j)

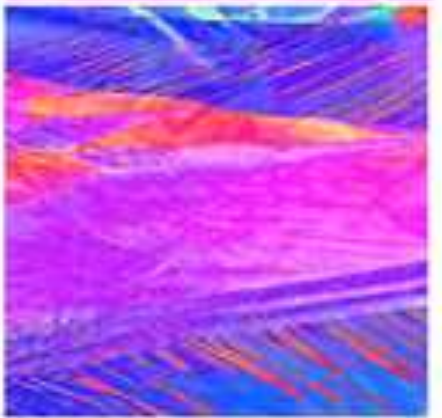



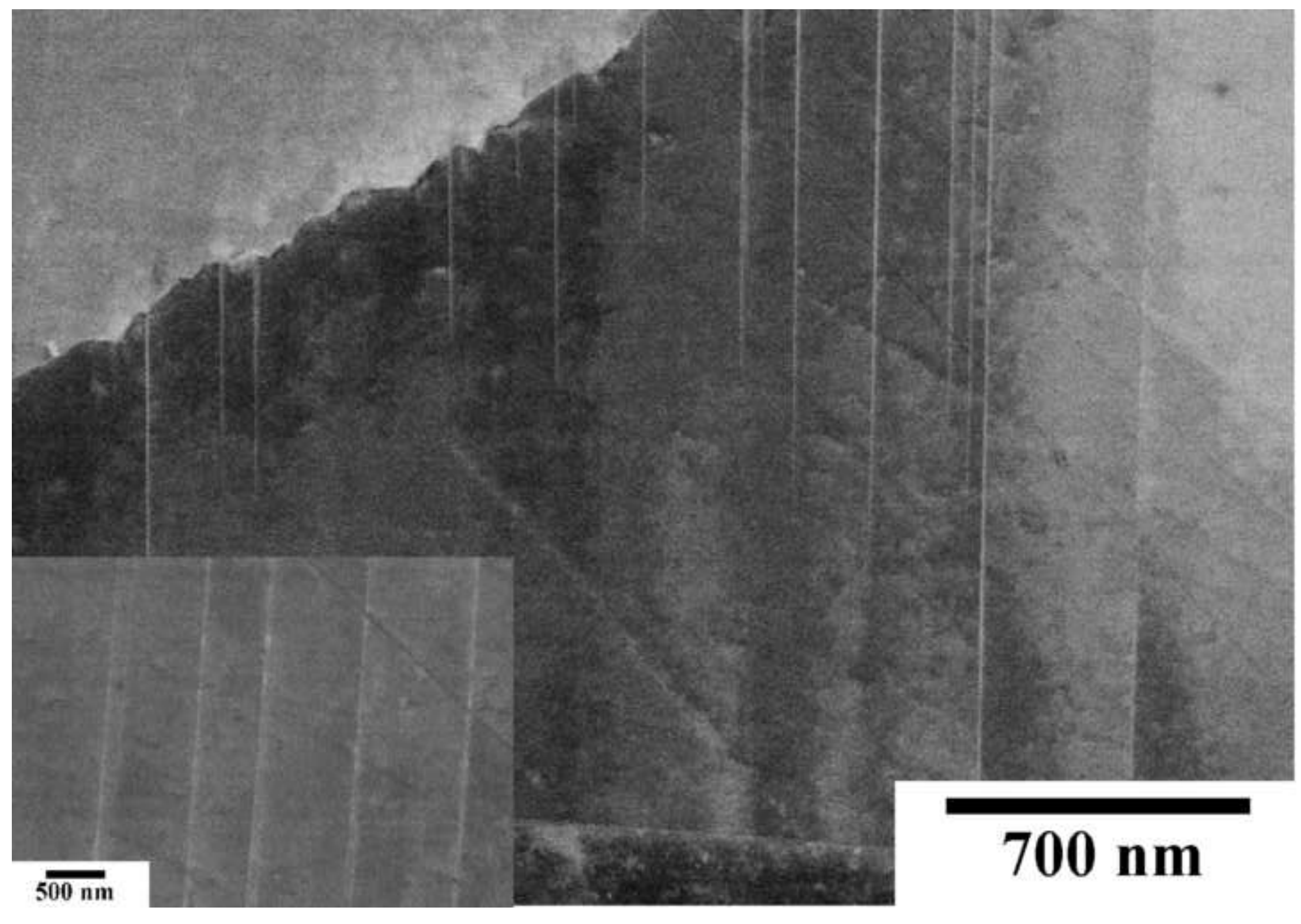

$$
\text { 政 }
$$

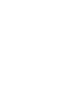

Figure 3
Click here to download high resolution image
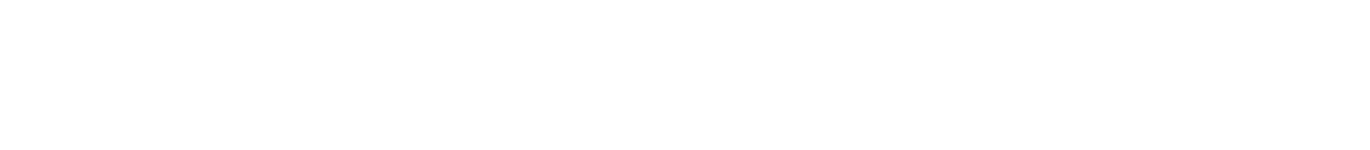

\section{$700 \mathrm{~nm}$

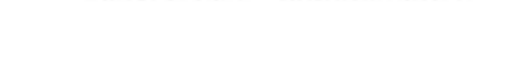

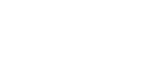



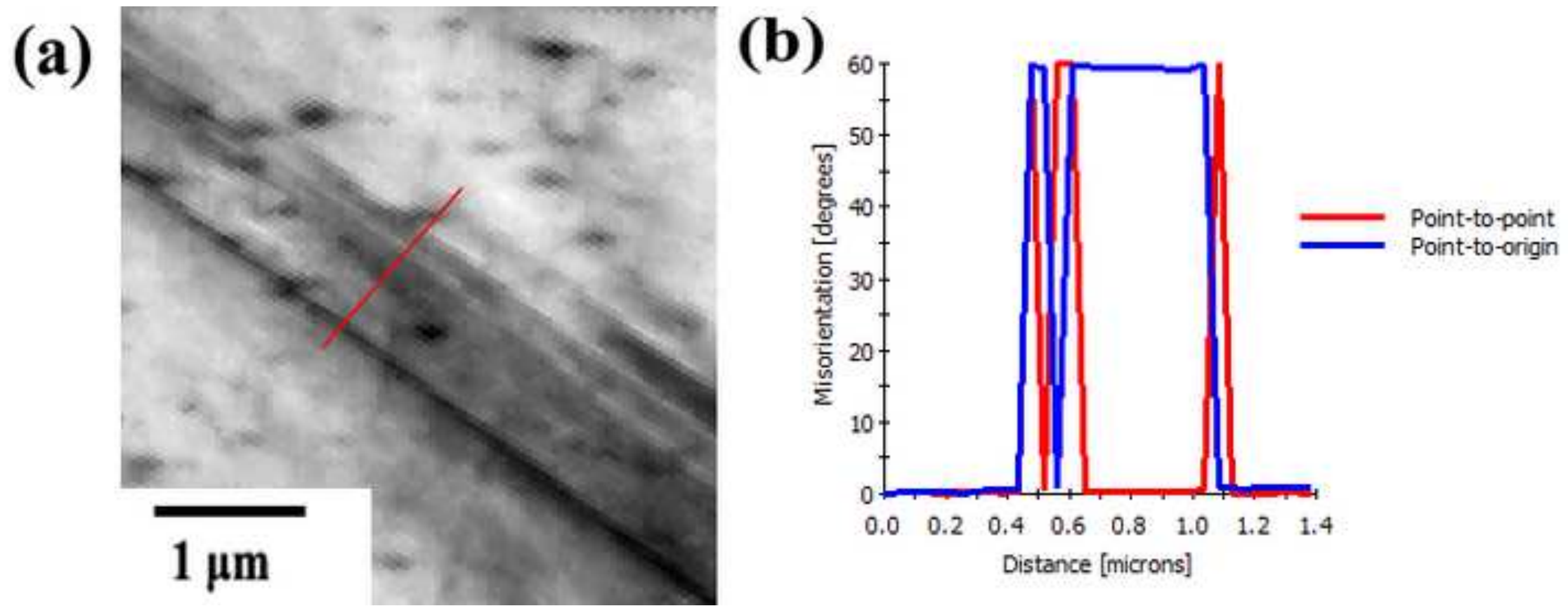
Click here to download high resolution image

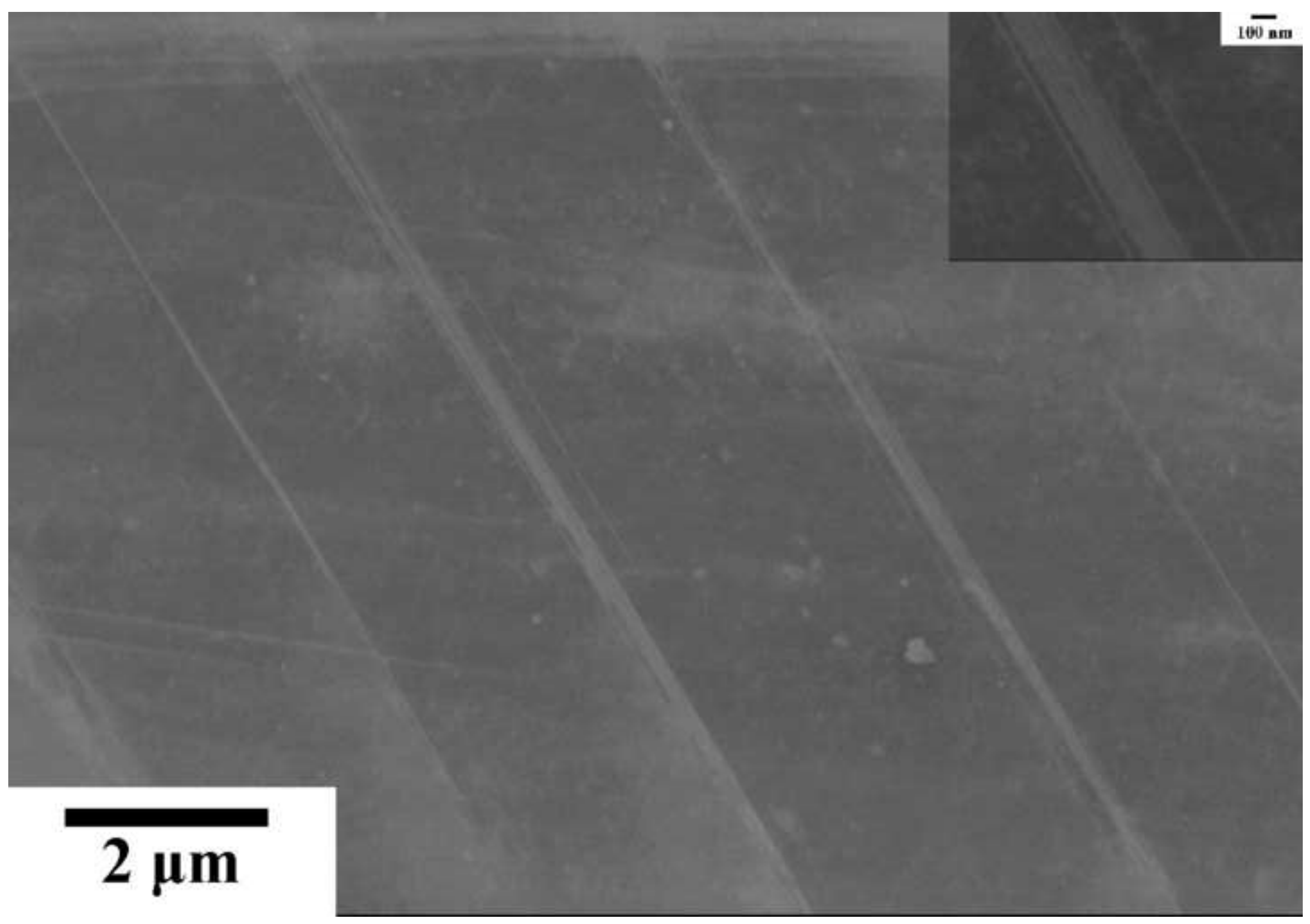

Figure 5

$2 \mu \mathrm{m}$ 
Click here to download high resolution image

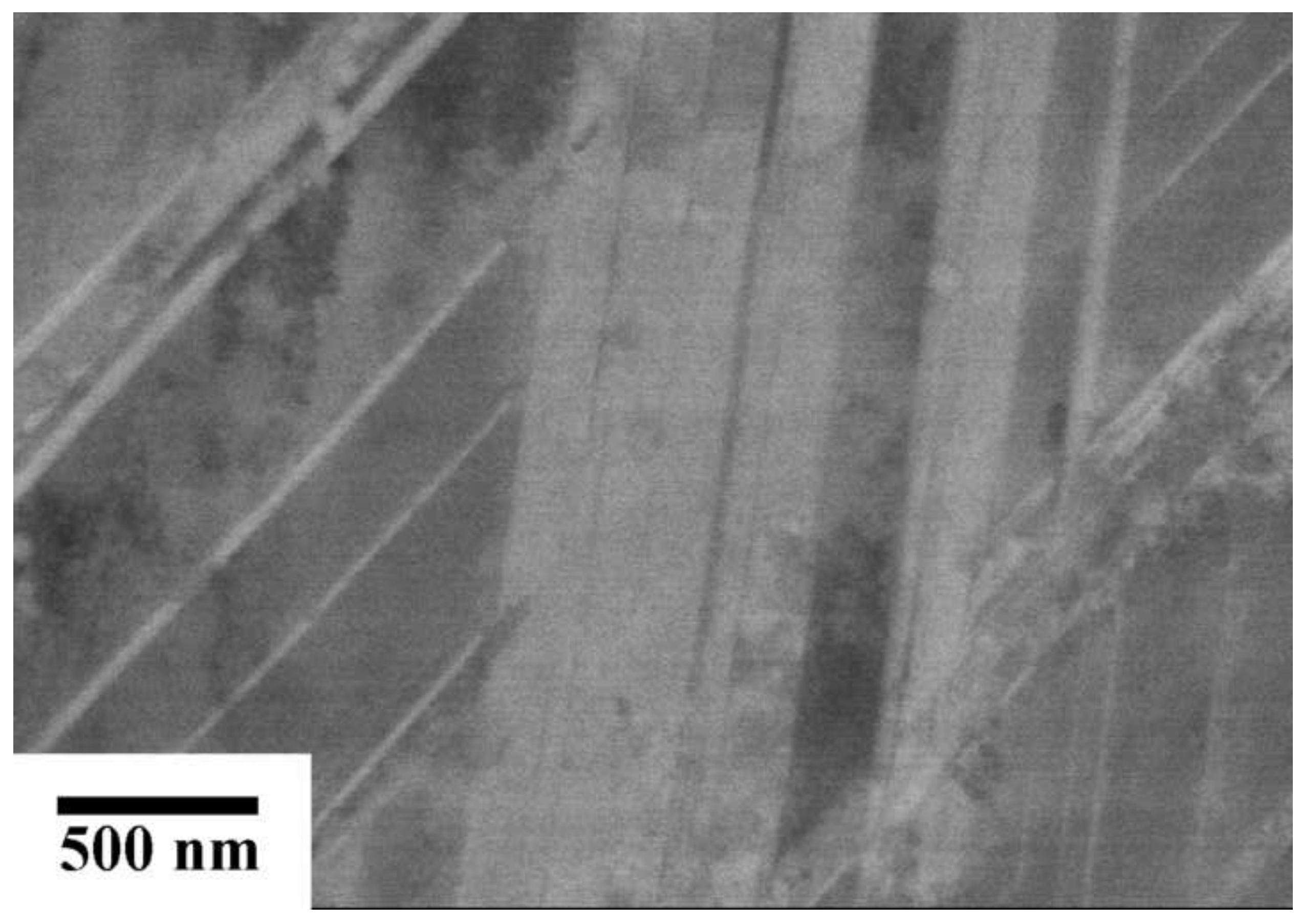

edown 


\section{Figure 7}

Click here to download high resolution image

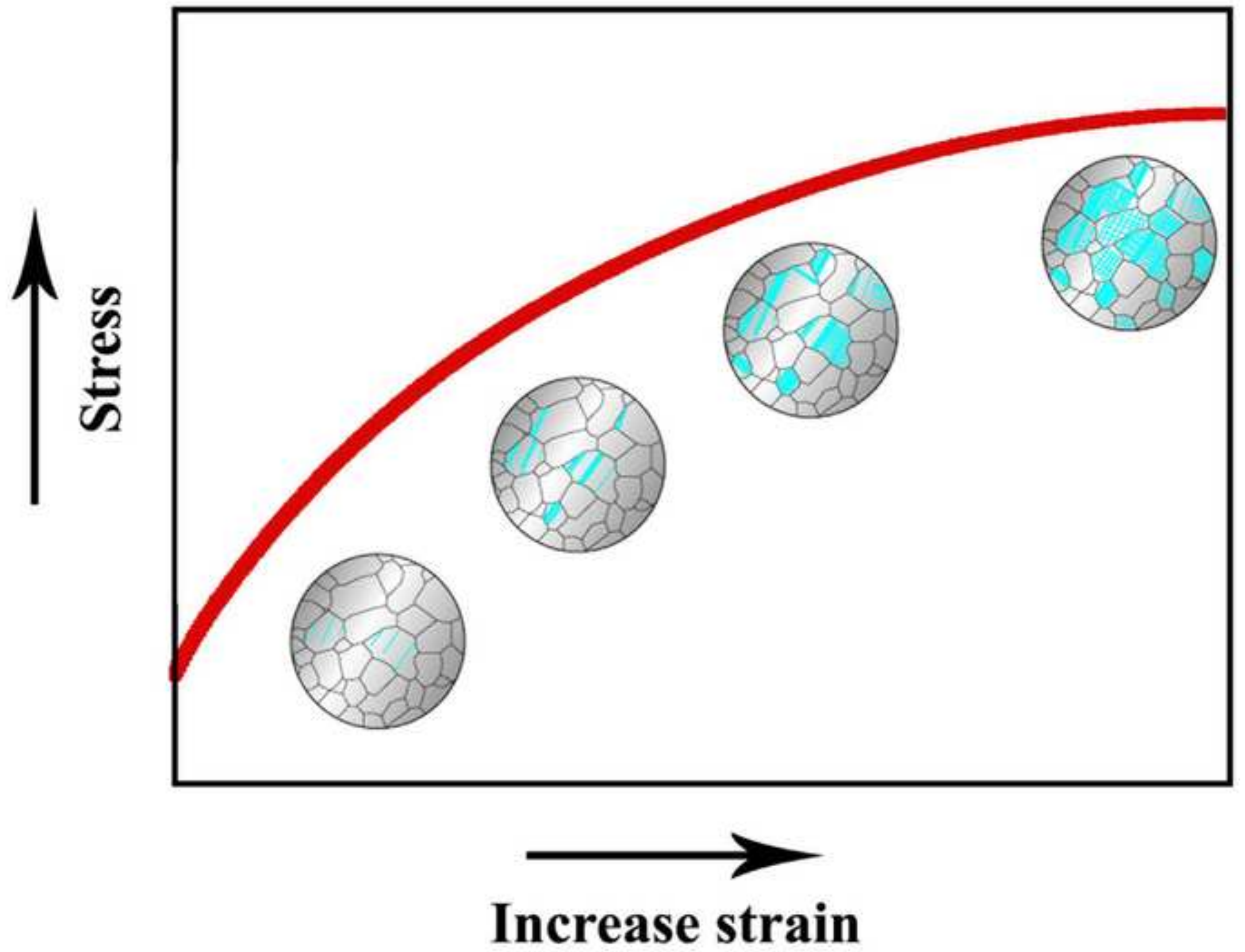


Figure 8
Click here to download high resolution image

(a)

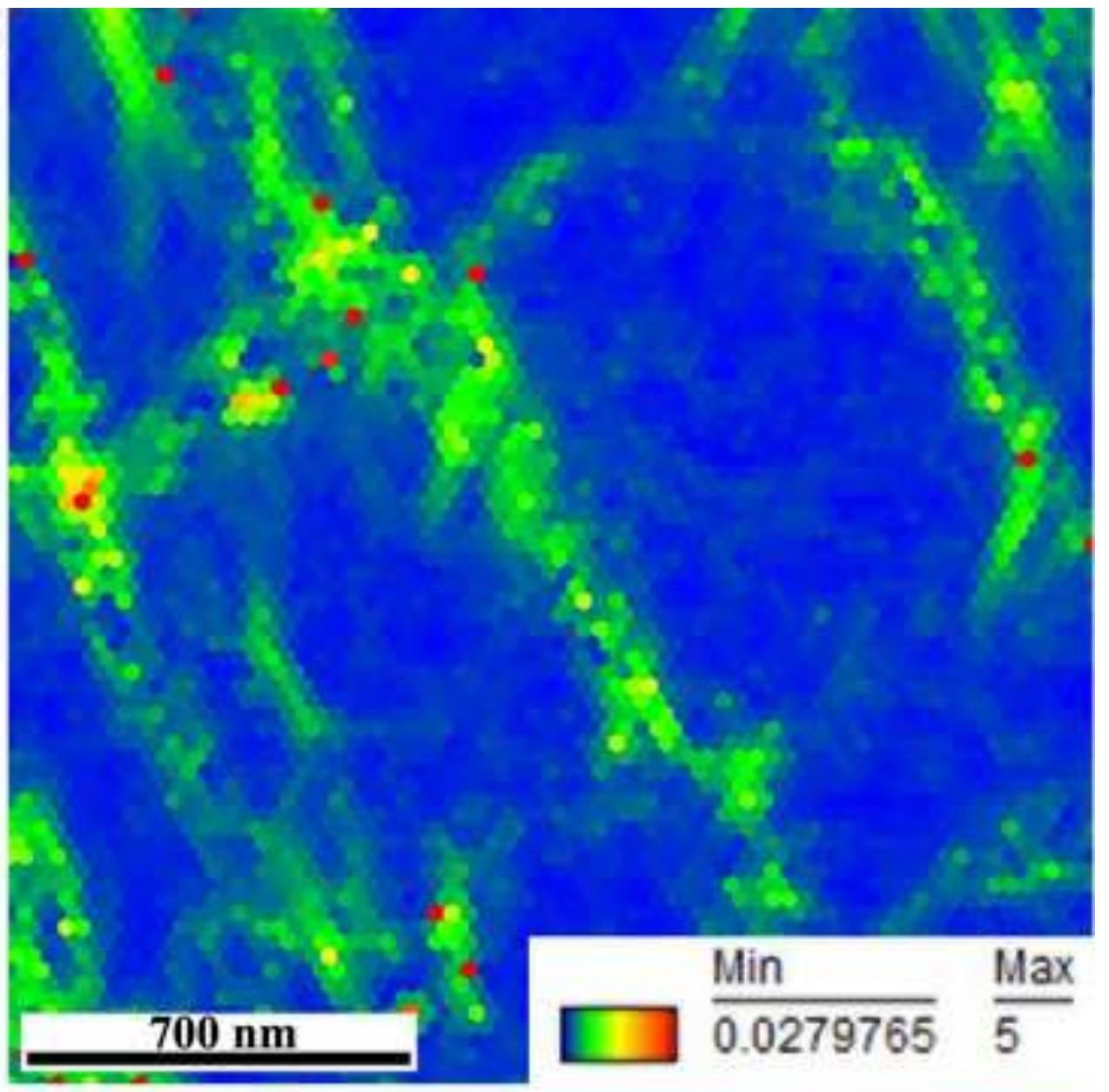

(b)

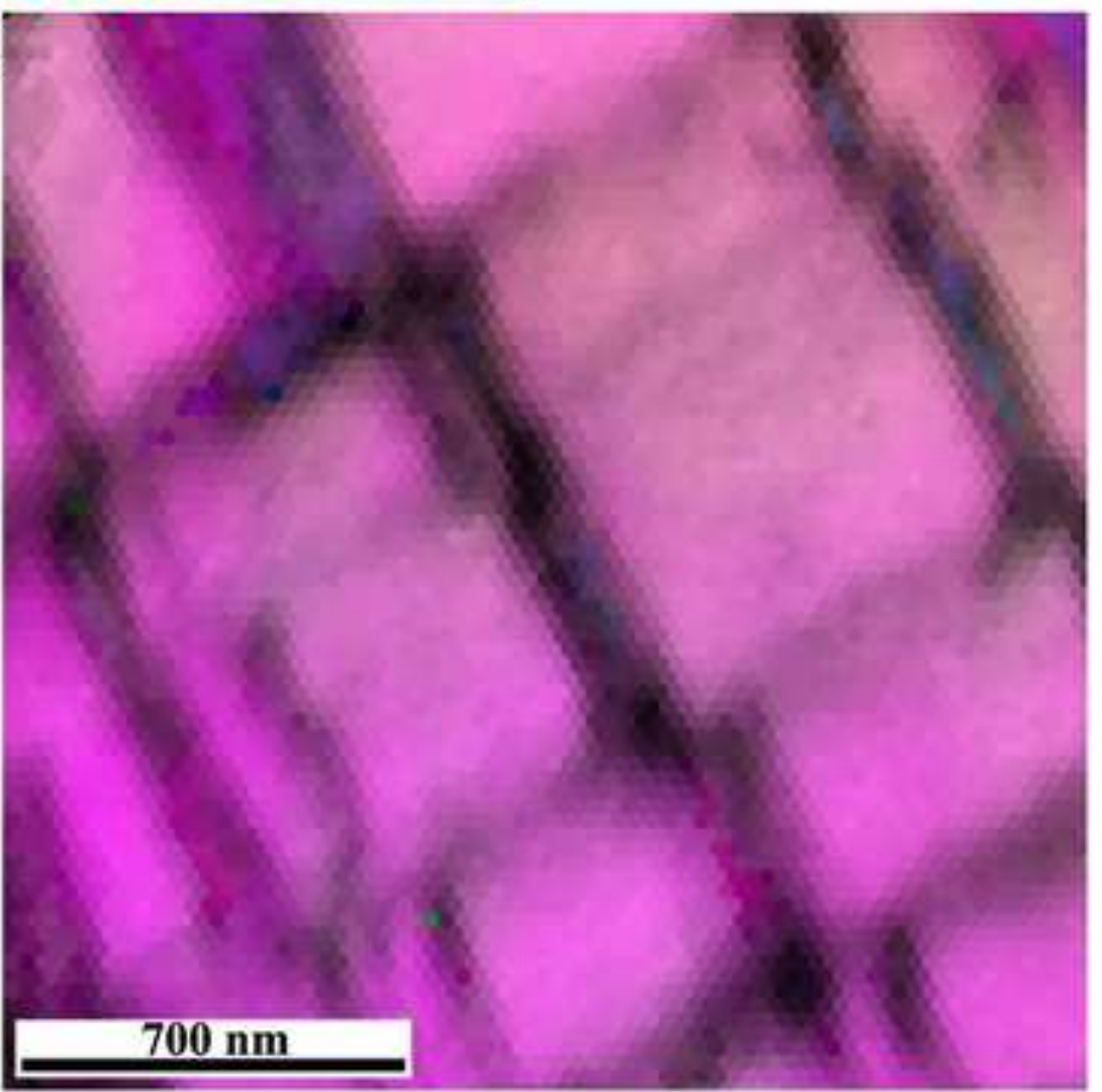

